\title{
LA MOCION DE CENSURA AL ALCALDE
}

\author{
POR \\ José A. LÓPEZ PELLICER \\ Profesor Titular de Derecho Administrativo
}

\begin{abstract}
SUMARIO: I. LA MOCIÓN DE CENSURA EN EL CONTEXTO DEL SISTEMA DEMOCRÁtico Y CONSTITUCIONAL.-II. REQUISITOS DE LA MOCIÓN DE CENSURA AL ALCALDE: 1. La iniciativa de la moción de censura. 2. El carácter uconstructivo" de la moción. 3. ¿Ha de ser motivada la moción de censura?-III. TRAMITACION DE LA MOCIÓN DE CENSURA: 1. Convocatoria de la sesión plenaria. 2. Posibilidad de presentación de mociones de censura alternativas. 3. Informe del Secretario de la Corporación. 4. Debate y votación. Efectos en caso de que la moción prospere.-IV. REVISIÓN JUDICIAL DEL ACUERDO DE DESTITUCIÓN
\end{abstract}

\section{LA MOCION DE CENSURA EN EL CONTEXTO DEL SISTEMA DEMOCRATICO Y CONSTITUCIONAL}

En la configuración que del municipio hace la vigente Constitución, en su artículo 140, el principio electivo define y caracteriza a este tipo de entidad local fundamentalmente como una entidad representativa, en cuanto que los miembros integrantes de sus órganos básicos, ayuntamiento y alcaldía, han de ser elegidos: los Concejales mediante elección de primer grado, y el alcalde, según la opción prevista en el citado precepto constitucional, bien mediante este sistema, esto es, por los vecinos, o bien en segundo grado, por votación de los concejales que hayan sido elegidos por aquéllos. Este basamento constitucional de la estructura organizativa básica del municipio, como una estructura de carácter representativo y por lo mismo democrática, confiere a este tipo de Administración pública local (1), un rasgo característico respecto de otros tipos de Administraciones territoriales que, como sucede con la del Estado y las de las Comunidades Autónomas, responden en su configuración jurídica a otro modelo diferente, el institucional-burocrático, supuesto que en la organización estatal y en la autonómica la virtualidad del principio representativo se concreta y manifiesta en el ámbito parlamentario y no en el administrativo.

(1) El articulo 140 de la Constitución se halla incardinado sistemáticamente bajo la rúbrica de «Administración Locals, del capitulo II del título VIII del texto fundamental. No cabe deducir de ello, sin más, que el municipio tiene un carácter meramente administrativo, porque no puede desconocerse en él, como dice la sentencia del Tribunal Supremo de 29 de junio de 1987 (Arz. 7139), un cierto componente político que le viene atribuido a la Corporación por el origen democrático de sus componentes, siendo precisamente ese componente político el motor de la vida municipal, cuyo respeto garantiza la Constitución. 
Ese rasgo peculiar del municipio, como entidad representativa y no sólo gestora - lo que es también común a la provincia, aunque ésta de forma menos básica y primaria-, rasgo que le viene dado por el origen democrático, electivo, de los miembros componentes de sus órganos básicos, es el que explica y justifica el que incluso se apliquen técnicas y mecanismos propios del ámbito parlamentario a las relaciones entre el órgano plenario de la Corporación municipal y el alcalde como órgano ejecutivo, en similitud - «servatis servandis»a las que con el ámbito estatal y en el autonómico se dan entre el legislativo y el Gobierno, cuando - como sucede en nuestro ordenamiento- el Presidente de este último órgano del Ejecutivo es elegido por el Parlamento. Es en este contexto político y constitucional, propio de un sistema parlamentario, en el que se sitúa la técnica de la moción de censura, que la Constitución regula en su artículo 113 $y$, en el ámbito regional, los diversos Estatutos de Autonomía, al regular el control del ejecutivo por el parlamento o asamblea legislativa (2).

En este contexto de democracia representativa y parlamentaria en el que se inserta así pues la técnica de la moción de censura, se sitúa el régimen local, que la acoge por ello entre las funciones $y$ atribuciones conferidas al pleno del ayuntamiento, como órgano de control del ejecutivo municipal. El artículo 22,3, de la Ley $7 / 1985$, de 2 de abril, reguladora de las bases del régimen local, establece que pertenece a este órgano municipal plenario «la votación sobre la moción de censura al alcalde, que se rige por lo dispuesto en la legislación electoral general». La fórmula, como técnica para destituir al alcalde, cuenta con precedentes en nuestro ordenamiento histórico (3), pero, a diferencia de lo que sucedía con el presidente de la diputación provincial, no se había previsto por la Ley de Elecciones Locales de 17 de julio de 1978, por lo que la remisión que el citado precepto de la Ley 7/1985 hace a la legislación electoral general no se completa formalmente hasta que la Ley Orgánica 5/1985, de 19

(2) En lo que se refiere a la moción de censura, en este ámbito y a efecto de las relaciones entre ambos órganos y la exigencia de responsabilidad del ejecutivo, su regulación varía según los Estatutos. Puede ser propuesta por un determinado número de parlamentarios, cuya proporción varía según las regulaciones (el Estatuto de la Región de Murcia, requiere al menos el 15 por 100 de los diputados regionales: artículo 33,4), debe incluir un candidato a la presidencia del Ejecutivo autonómico (carácter aconstructivo» de la moción) y es precisa la aprobación por mayoría absoluta para que la censura prospere. Vid. por todos, S. MUÑOZ MACHADO: Derecho público de las Comunidades Autónomas, II, p. 59 y s. (Edit. Civitas, Madrid, 1984).

(3) El Estatuto Municipal de 8 de marzo de 1924 preveía que el alcalde podrá ser destituido por acuerdo de dos terceras partes del número legal de concejales (artículo 102). Y la Ley Municipal de 31 de octubre de 1935 (artículo 81) decía que el alcalde elegido por el Ayuntamiento podrá ser destituido por el voto de la mayoría absoluta de los Concejales que legalmente formen la Corporación, o por votación popular en que así lo acuerde la mitad más uno de los electores (aunque limitaba esta última fórmula de destitución, en todo caso, la del alcalde que hubiere sido elegido por el pueblo). 
de junio, del régimen electoral general, regula dicha técnica en su artículo 197.

Admitida no obstante, en la Ley de Elecciones Locales de 1978, la posible destitución del presidente de la diputación, la jurisprudencia del Tribunal Supremo interpretó que la del alcalde también entonces era posible, a pesar de la laguna legal en cuanto a éste, atendiendo al criterio de la analogía (artículo 4,1, del Código Civil) y al principio de "contrarius actus», que permitía en consecuencia asimismo la destitución del alcalde por mayoría absoluta de la Corporación municipal (4). Doctrina que enlazaba con la mantenida por el Tribunal Constitucional en Auto 52/1983, de 9 de febrero, en cuyo F. J. 2. dice que «debemos entender que el derecho en permanencia en un cargo público de carácter electivo, en el caso de que se encuentre en el artículo $23 \mathrm{CE}$, no podría nunca excluir el cese del titular por la voluntad de las mismas personas que lo eligieron o la voluntad del mismo órgano, formada de acuerdo con el Ordenamiento jurídico» (5).

El carácter democrático del ayuntamiento, como órgano de representación municipal, determina también el que considerase, asimismo, por la jurisprudencia del Tribunal Supremo, que a pesar de que la citada Ley Orgánica Electoral 5/1985 dispusiera en su transitoria 3. a que lo establecido en su artículo 197, sobre la moción de censura al alcalde, se demorase al momento en que se celebraran las primeras elecciones locales siguientes a la entrada en vigor de esta Ley - condición que se cumpliría con las elecciones locales de junio de 1987-, ello no obstante el alto Tribunal admitiera de modo reiterado la posibilidad de mociones de censura presentadas por los concejales, por cuanto «el aplazamiento de la tramitación de tales mociones de censura hasta después de las elecciones próximas, supone un menoscabo del libre y pleno ejercicio del cargo público de Concejal directamente elegido por los ciudadanos, configurando tales mociones de censura como un verdadero funcionamiento democrático de los Ayuntamientos; hallándonos, pues, ante la presentación de una moción de censura, es evidente que procedía su tramitación, si el

(4) Sentencia del Tribunal Supremo de 14 de julio de 1983 (Arz. 3993) y 10 de octubre de 1984 (Arz. 4952). En la doctrina, M. Rebollo Puig: aLa moción de censura en la Administración Local», en el número 227 de esta Revista, pp. 464 y ss. L. MoRell OcAñA: Régimen Local Español, I, pp. 563 y s. (Civitas, 1988). L. Cosculluela MONTANER: Las elecciones locales, en el Tratado de Derecho Municipal, dirigido por S. Muñoz Machado, I, p. 724 (Civitas, 1988).

(5) Cosculluela Montaner: Ob. cit., p. 724. Con anterioridad a dicho auto, el Tribunal Constitucional ya había defendido la constitucionalidad de cualquier previsión del legislador ordinario de la moción de censura de los alcaldes, al entender que el artículo 23 CE no otorga a los electos un derecho de permanencia en el cargo que impida su destitución por el mismo órgano que lo eligió (Sentencias del Tribunal Constitucional 5/1983, de 4 de febrero, y 30/1983, de 26 de abril). El Tribunal Supremo se ha referido de forma reiterada a dicha situación, anterior a la normativa actual, en varias sentencias, como la de 15 de marzo de 1986 (Arz. 1590, F.J. 2. ${ }^{\circ}$ ), 3 de junio de 1986 (Arz. 3319, F.J. 5. ), 25 de mayo de 1987 (Arz. 3479) y 11 de mayo de 1987 (Arz. 5854), entre otras. 
único obstáculo que se opusiera a ello fuera, únicamente, su improcedencia por razón del tiempo en que se pretende hacerla valer, y no por otras circunstancias» (6).

El sentido democrático en el que - ex Constitutione- se fundamenta el régimen de la institución municipal ha servido, así pues, a la jurisprudencia para determinar y superar cualquier obstáculo que pudiera derivar no ya sólo de una situación de anomia jurídica, sino también de aquellas otras circunstancias en que, como la del referido aplazamiento transitorio, pudiera entenderse que desvirtuaba de algún modo la aplicación del principio constitucional, y ello aún a pesar de las dificultades que la falta de regulación de las condiciones y modo de operar a tal efecto planteaba inevitablemente. Si era preciso, se apelaba a la naturaleza de las cosas, propia del nuevo sistema democrático, y a la necesaria coherencia entre el modo de elegir los alcaldes y el modo de destituirlos (sentencia del Tribunal Supremo de 7 de abril de 1988, Arz. 2662). Superada, no obstante, la situación precedente, en el ordenamiento actual, con la regulación de las condiciones que ha de cumplir la moción de censura al alcalde, y el procedimiento que, para su trámite, ha de seguirse, parece oportuno volver sobre la institución para examinar estos elementos, teniendo en cuenta asimismo las aportaciones de la última jurisprudencia contencioso-administrativa.

\section{REQUISITOS DE LA MOCION DE CENSURA AL ALCALDE}

Para que una moción de censura al alcalde pueda ser sometida a debate y votación por el ayuntamiento, en la forma que después se verá, es necesario que la misma reúna los requisitos establecidos en la Ley Orgánica 5/1985, de Régimen Electoral General (artículo 197), y que se refieren a la forma de promover la iniciativa y al carácter positivo o "constructivo» que la moción ha de tener.

\section{La iniciativa de la moción de censura}

El primer requisito que ha de cumplir la moción de censura consiste en que la misma ha de ser formulada al menos por una tercera parte de los concejales (artículo 197,2, de la Ley Orgánica $5 / 1985)$, porcentaje que ha de entenderse referido al número de concejales que legalmente constituyen la Corporación municipal. Se establece sin embargo, legalmente, la limitación de que ningún concejal podrá suscribir, durante su mandato, más de una moción de

(6) Sentencia de 18 de noviembre de 1986 (Arz. 6732), que reiteraba otras de 3, 15 y 17 de marzo y 15 de julio de 1986 (Arz. 1090, 1091 y 4360). 
censura, de modo análogo a como establece en su artículo 113,4, la Constitución respecto a la moción de censura al Gobierno de la Nación.

Ahora bien, para que esta limitación opere legalmente, es preciso que la moción de censura que, en su caso, se hubiere presentado con anterioridad, haya sido sometida a deliberación y votación por el pleno de la Corporación local. No basta con que se haya formulado una moción de censura al alcalde para que, sin más, los concejales que la hubieran suscrito no puedan hacerlo de nuevo si la anterior no ha sido objeto de trámite y decisión de forma reglamentaria. Asi se ha considerado por el Tribunal Supremo en las sentencias de 12 y 13 de mayo de 1987 (Arz. 3333 y 3334) y de 2 de julio de 1987 (Arz. 8109). Esta última sentencia considera que nada impedía una nueva moción, en cuanto que la solicitada en un momento anterior no llegó a celebrarse, al no existir debate o deliberación, ni sobre la urgencia de la moción (que había sido presentada para ser tratada como moción de urgencia en un pleno ordinario), ni sobre el fondo de la misma, ni votación ni proclamación del acuerdo de cese y nuevo nombramiento, como expresamente sentó el Tribunal Supremo en sentencia de 4 de noviembre de 1986 (Arz. 6155). Para que pueda hablarse de doble moción de censura ha de haberse celebrado la anterior, como dice el propio Tribunal en la sentencia de 13 de mayo de 1987 (Arz. 3334), siguiendo la doctrina que ya se había sentado en las sentencias de 15 de septiembre de 1986 y las que en ella se citan.

La causa de la limitación de mociones de censura, según considera la sentencia de 12 de mayo de 1987 (Arz. 3333), se halla en que estas mociones no obstaculicen por su reiteración la acción de gobierno, a la que no puede oponerse el derecho fundamental recogido en el artículo 23,1 , de la Constitución cuando, como sucede en el caso que la sentencia se refiere, no pudo ejercerse este derecho ante la injustificada negativa del alcalde a que la moción contra él presentada fuera sometida a deliberación y votada.

Por lo demás, la moción de censura habrá de ser formalizada mediante escrito, que ha de ser presentado en el Registro General de la entidad local (7), y que ha de ser suscrito al menos por la tercera parte de los concejales, según queda señalado.

\section{El carácter «constructivo» de la moción de censura}

De manera análoga a como está previsto en el régimen parlamentario de la moción de censura, contenido en el artículo 113 de la Constitución - según el cual ha de incluir en su propuesta un

(7) Artículo 107,2, del Real Decreto 2568/1986, de 28 de noviembre, por el que se aprueba el Reglamento de Organización, Funcionamiento y Régimen Jurídico de las Entidades Locales. 
candidato a la Presidencia del Gobierno-, el artículo 197 de la Ley Orgánica 5/1985 establece que la moción de censura al alcalde ha de cumplir, entre otros requisitos, el de incluir el nombre del candidato propuesto para alcalde; aunque a diferencia de lo que sucede en el régimen general de elección de éste, en la sesión constitutiva de la Corporación, regulada en el artículo 196 de la propia Ley Orgánica (8), en el supuesto especial de la moción de censura viene modificado en cuanto cabe legalmente la posibilidad de que cualquier concejal, aunque no haya encabezado la lista de las elecciones, sea propuesto como candidato a la alcaldía (9).

La moción de censura al alcalde se configura, así pues, no como una mera propuesta dirigida a conseguir la destitución del titular de la alcaldía, sino como una propuesta compleja, en cuanto que ha de incorporar y contener, además, una propuesta de sustitución del mismo por otro titular, entre quienes ostentan la condición de concejal. $Y$ aunque no se determina de modo expreso, cabe deducir implícitamente del artículo 197,3, de la Ley Orgánica 5/1985 que, como es lógico, es preciso que el candidato propuesto haya aceptado dicha candidatura, en razón de los términos potestativos en que el precepto aparece redactado y por comparación con el automatismo de la fórmula que, para la elección del alcalde, en la sesión constitutiva del ayuntamiento, se regula en el artículo 196 de la propia Ley Orgánica (10).

La sentencia del Tribunal Supremo de 2 de julio de 1987 (Arz. 8109) dice que si en el sistema jurídico español todas las mociones de censura se caracterizan por su carácter positivo, parece lógico admitir que el cese discutido requiera un doble acto, la votación del cese y la elección del nuevo alcalde, ambos por mayoría absoluta, a fin de dotar de estabilidad a los órganos municipales, evitando que minorías coaligadas sean capaces de impedir al gobierno de un ente, pero incapaz de ofrecer una alternativa viable, y de ahí la imposibilidad de mantener el régimen general de elección de Alcalde, en estos casos, sin que pueda confundirse el supuesto de la vacante en la alcaldía con el caso específico que ahora se contempla, interpretación que viene a aceptar la nueva normativa electoral.

Otra sentencia del mismo Tribunal, de 1 de junio de 1988 (Arz. 4519) dice también a este respecto, que aún antes de que la nueva

(8) Según el cual pueden ser candidatos los concejales que encabecen las correspondientes listas (artículo 196,a, Ley Orgánica 5/1985).

(9) Artículo 197,3, de la Ley Orgánica 5/1985. En consecuencia, por esta vía la reconstrucción de una mayoría gobernante se puede hacer sin contar con el líder - primer cabeza de lista- del partido más votado si éste accedió a la alcaldia. El paso de un gobierno monocolor a una alianza entre grupos puede exigir este sacrificio, correlato quizá de un desgaste producido por la gestión llevada a cabo en minoría (Morell Ocaña, L., Ob. cit., en la nota 4, p. 565).

(10) Asi se requiere, a fortiori, en el supuesto análogo de la moción de censura al Gobierno, en el articulo 175,2, inciso final, del Reglamento del Congreso de los Diputados. 
legislación local asi lo haya establecido -ejemplo art. 197,2, de la Ley Orgánica de 19 de junio de 1985-, la moción de censura del Alcalde tenía que ser constructiva, y a esta solución se llega con una interpretación sistemática de nuestro ordenamiento jurídico, coherente, es decir, inteligible, de elementos interrelacionados; y la coherencia se rompería si se admitiera que el criterio constitucional previsto para la censura del Presidente del Gobierno (moción constructiva) puede alterarse - sin norma expresa contraria - para supuestos en que el carácter de la moción no estuviera claramente expresado.

\section{3. ¿Ha de ser motivada la moción de censura?}

La Ley Orgánica 5/1985 no exige que la moción de censura al alcalde sea motivada. De algunas sentencias del Tribunal Supremo se deduce, sin embargo, que esta moción ha de venir fundada en la concurrencia de una causa justa. Así se considera por la sentencia de 1 de junio de 1988 (Arz. 4519), según la cual «atribuye la sentencia de instancia a este Tribunal Supremo la extraña doctrina de que es innecesario alegar justa causa. Esta no es la doctrina de este Tribunal. Pero aunque lo fuera tendría que ser rectificada, porque admitir que una censura pueda prosperar sin justa causa sería tanto como premiar un comportamiento arbitrario de los poderes públicos, siendo así que la arbitrariedad en la actuación de éstos se halla expresamente prohibida por el artículo 9.3 de la vigente Constitución».

Sin duda, esta última sentencia se refiere a la tesis mantenida en las anteriores de 27 de marzo de 1984 (Arz. 1494) y 21 de abril de 1987 (Arz. 2980). La primera de éstas decía que la exigencia de causa fundada, es una consecuencia derivada de la necesidad de evitar arbitrariedades que redundarian en perjuicio del servicio público y del interés general del pueblo al que se han de enderezar los refuerzos y la actividad de la Corporación que ha de regir sus destinos, pero al propio tiempo, la causa ha de ser de aquéllas que fracturan la confianza del electorado y en este caso de los Concejales electores en la persona del que resultó elegido Presidente de la Corporación y que de paso comporten desprestigio de la misma, en orden al buen concepto público de la institución democrática, con lo que se perfilaría con clara silueta aquello que debe entenderse por causa fundada y justa. Y la sentencia de 21 de abril de 1987 (Arz. 2980) se refiere a la procedencia de hacer constar en la moción de censura «hechos razonables que la hagan necesaria, aducidos con claridad y responsabilidad".

Ahora bien, sin perjuicio de que, en su caso, existan otras razones de fondo que la fundamenten, la causa legitimadora de la moción de censura se halla jurídicamente en la pérdida de la confianza de la 
Corporación municipal en el alcalde. Así cabe deducirlo de otras sentencias del Tribunal Supremo, como la de 14 de julio de 1983 (Arz. 3993), que poco después de la sentencia del Tribunal Constitucional de 4 de febrero de 1983, que sentaba la diferencia, atendiendo a la forma de elección distinta, entre el cese de Concejales y alcaldes, deducía aquélla que «parece lógico atribuir a ese electorado -esto es, a los propios concejales - la facultad de cesar como alcalde al que un día fuera elegido, cuando circunstancias sobrevenidas aconsejen que la Presidencia del Ayuntamiento sea renovada» - y añade - «Son esas imputaciones, pese a su singular gravedad, reveladoras... de un estado de opinión que... revela la falta de confianza que el alcalde merece por parte de los demás componentes de la Corporación". Y en esta misma línea, otra sentencia del Tribunal Supremo, ésta de 10 de octubre de 1984 (Arz. 4952), considera que en cuanto a la grave causa - segundo tema polémico-, aunque se hizo hincapié, con análisis del mismo, en Sentencias de esta Sala de 14 de julio de 1983 y 27 de marzo de 1984, ello fue debido a que particularmente se cuestionó fácilmente su existencia, pero sin que de ahí pueda generalizarse la necesidad de que se produzca realmente, pues no está dentro de las facultades de esta jurisdicción, hacer juicios de valor de conductas y voluntades de los concejales electores del Alcalde, en punto a las causas que motiven la pérdida de su confianza posterior en el inicialmente elegido. Con ello, pues, se advierte, que no pueden extrapolarse de sus precedentes fácticos que originan las actuaciones que dieron lugar a esas sentencias, que, sin embargo, dejan bien claro que no está dentro del cometido de la Ley $62 / 78$, la valoración de los motivos de cambio de voluntad de los concejales que eligieron y luego destituyeron al alcalde.

La destitución del alcalde aparece así, como señala Morell Ocaña (11), jurídicamente amparada en la sola y exclusiva razón de la desaparición de la confianza inicialmente puesta en el elegido. Su fundamento - añade- es únicamente éste: entre el alcalde y los concejales ha de existir un vínculo de confianza; de lo contrario, se entiende engendrado un riesgo para la gestión municipal, riesgo que se obvia con la sustitución del alcalde.

En defitiniva, de lo dicho cabe deducir, así pues, que, aún cuando existieren razones y circunstancias que por su gravedad justifiquen la moción de censura, no es legalmente necesario expresarlas en ella, para demostrarla, supuesto que el régimen legal vigente no establece esta exigencia. No es óbice ello a que pueda ser -o seapolíticamente oportuno y conveniente determinar las circunstancias que concurran, en su caso, a fin de justificar ante la opinión pública la causa o causas en que se fundamenta la moción y, de esta manera,

(11) Ob. cit., en nota 4 , pp. 564 y s. 
explicar las razones de la propuesta y la pérdida de confianza en la gestión del alcalde, sobre lo que habrá de pronunciarse el órgano plenario de la Corporación local en definitiva. Aspecto político de la motivación que no trasciende, sin embargo, al plano jurídico, ni en consecuencia al orden jurisdiccional, como revela en este aspecto la citada sentencia de 10 de octubre de 1984 (12).

\section{TRAMITACION DE LA MOCION DE CENSURA}

Como la atribución para conocer y decidir sobre la moción de censura al alcalde está legalmente conferida al pleno del ayuntamiento, según la legislación de régimen local (13), la legislación electoral presupone este elemento competencial y se limita a establecer ciertos requisitos formales, que se refieren fundamentalmente al quórum de votación, que ha de ser el de la mayoría absoluta del número legal de concejales, y que en caso de darse, determina que el candidato propuesto en la moción aprobada quede proclamado alcalde de modo automático, «ex lege» («quedará proclamado como tal en caso de prosperar la moción»), conforme determina el artículo 197,1 y 2, de la Ley Orgánica 5/1985. La legislación de régimen local remite a los reglamentos orgánicos de las entidades locales los aspectos relativos al procedimiento y el debate de la moción de censura, pero por influjo del régimen contenido en el artículo 113 de la Constitución, establece determinadas exigencias que implican un mayor rigor para la tramitación de la propuesta, como vamos a ver.

\section{Convocatoria de la sesión plenaria}

El procedimiento ha de iniciarse con la presentación de la moción de censura, en la forma que ha quedado expuesta, y la solicitud de sesión extraordinaria, que ha de ser suscrita al menos por la tercera parte de los concejales, según el artículo 197,2, de la Ley Orgánica $5 / 1985$. Se exceptúa así el régimen general del artículo 42,2,a), de la Ley $7 / 1985$, de bases del régimen local, en que basta que la petición de sesión extraordinaria se formule por la cuarta parte del número legal de los miembros de la Corporación. Al no establecerse nada en contra, es aplicable el régimen general contenido en este último precepto legal básico, que establece que la celebración de la sesión por el pleno no podrá demorarse por más de dos meses desde que

(12) Vid. asimismo, al comentar esta sentencia SANtolaya MACHETt: «Posibilidad de cese de los alcaldes mediante una moción de censura», en Revista de Administración Pública, núm. 108, p. 264.

(13) Artículo 22,3, de la Ley 7/1985, de 2 de abril, y 50,1, del Real Decreto 2568/1986, de 28 de noviembre.

REVISTA DE ESTUDIOS.-2 
fuera solicitada; aunque hay que tener en cuenta que otro precepto legal, que tiene asimismo carácter básico, el contenido en el artículo 48,1 , del Texto refundido aprobado por el Real Decreto Legislativo $781 / 1986$, de 18 de abril (14), establece que el presidente de la Corporación Local viene obligado a convocar la sesión extraordinaria dentro de los cuatro días siguientes al de la solicitud (15). Hay que distinguir, por ello, entre este plazo corto para efectuar la convocatoria de la sesión extraordinaria, y el plazo para celebrar esta sesión, que será como máximo de dos meses, a contar asimismo desde la solicitud (presentada en el Registro General de la Entidad), y como mínimo de siete días (16).

Este último plazo viene a equivaler, en cierto modo, al período que en el ámbito parlamentario suele denominarse «de enfriamiento» $y$ que se refiere al número de días que ha de transcurrir entre el de presentación y el de votación de una moción de censura (17). La diferencia de régimen entre el procedimiento parlamentario y el de sesiones de las entidades locales determina el que el cómputo del plazo en este último ordenamiento se refiera, respecto al "dies ad quem", al día en que, como mínimo, ha de celebrarse la sesión extraordinaria para debatir y votar la moción, y que el alcalde habrá de convocar, como se ha indicado, dentro de los cuatro días siguientes al de la solicitud. Estos plazos han de computarse en días hábiles, excluyéndose el cómputo los días festivos, conforme al artículo 60 de la vigente Ley de Procedimiento Administrativo.

Una vez presentada la moción de censura, con solicitud de convocatoria de la correspondiente sesión extraordinaria y específica, para proceder al debate y votación del asunto, el alcalde, como presidente de la Corporación, vendrá obligado a convocar el pleno de la misma, por aplicación del régimen general de sesiones a que antes

(14) Precepto cuyo carácter básico viene fijado por la disposición final 7.a del propio Real Decreto $781 / 1986$.

(15) Vid. en este sentido, la sentencia del Tribunal Supremo de 14 de julio de 1987 (Arz. 7149), teniendo en cuenta que el artículo 48,1, del Texto refundido actual reproduce esta exigencia, que procede del artículo 294 de la Ley de Régimen Local de 24 de junio de 1955

(16) El artículo 107,3, del Real Decreto 2568/1986, de 18 de noviembre, establece que entre la presentación de la moción de censura y la celebración de la sesión extraordinaria deberán transcurrir, al menos, siete dias.

(17) El artículo 113,3, de la Constitución éstablece que la moción de censura no podrá ser votada hasta que transcurran cinco dias desde su presentación. Este plazo o periodo de aenfriamienton, consagrado en el constitucionalismo contemporáneo, tiene por objeto evitar que la presentación de una moción de censura y su inmediata votación, por sorpresa diríamos, sólo sea respaldada por una mayoría ocasional, así como que el voto de la moción se efectúe tras un debate apasionado, que puede concitar transitoriamente una mayoría contraria al Gobierno, o cuya precipitación impida a éste la búsqueda y la negociación de sus apoyos parlamentarios para impedir su derrota (MONTERo GiBert, J. R.: «Moción de censura», en Diccionario del Sistema Político Español, dir. por J. I. González Espinar, Akal, 1984, pp. 510 y s.). 
se ha hecho mención. Solamente podrá denegar la convocatoria en el caso de que la moción de censura no reúna los requisitos establecidos en la Ley Orgánica 5/1985, de 19 de junio, respecto a la iniciativa y carácter «constructivo» que ha de tener la moción, conforme establece el artículo 197 de esta Ley. No será necesario, según lo dicho, que en la moción se expresen las causas que puedan motivar la pérdida de confianza en el alcalde que pretenda destituirse.

La denegación por el alcalde de la convocatoria habrá de ser motivada, por tanto, con base en el incumplimiento de alguno de los requisitos establecidos para la moción de censura en el citado precepto de la Ley Orgánica electoral, a que nos hemos referido con anterioridad (18). Por ello, la jurisprudencia del Tribunal Supremo ha considerado que la no convocatoria de la sesión plenaria constituye en otro caso, una violación del artículo 23,1 , de la Constitución, es decir, del derecho de los ciudadanos a participar en los asuntos públicos por sí o por medio de representantes. Así, con la lógica diversidad de matices propios de cada caso, en las sentencias de 15 de marzo de 1986 (Arz. 1090), de 3 de junio de 1986 (Arz. 3369), 18 de noviembre de 1986 (Arz. 6732), 13 de mayo de 1987 (Arz. 3334), 8 de junio de 1987 (Arz. 4009), 15 de septiembre de 1987 (Arz. 6008), 5 de octubre de 1987 (Arz. 6700), 2 y 14 de julio de 1987 (Arz. 7149 y 8109, respectivamente) y 14 de enero de 1988 (Arz. 273). Entre ellas, la de 5 de octubre de 1987 considera que no estaba legalmente restringido el derecho de los Concejales a pedir la convocatoria de sesión extraordinaria cuando concurrían los requisitos objetivos $y$ formales bastantes al efecto; y en consecuencia, se ordena al alcalde a convocar de forma inmediata un pleno extraordinario en que se debata y vote la moción. La consecuencia que resulta, así pues, de la infracción en este supuesto del artículo 23,1, de la Constitución, en cuanto contempla un derecho fundamental, es que, conforme al artículo 53,2, de la misma, este derecho cuenta con la protección especial de la Ley $62 / 1978$, de 26 de diciembre, en cuanto a la garantía contencioso-administrativa (19), y en último término, con la del recurso de amparo constitucional.

(18) Vid. la sentencia del Tribunal Supremo de 21 de abril de 1987 (Arz. 2980), relativo a un caso en que el alcalde deniega la solicitud de celebrar un pleno extraordinario, fundándose la denegación en que la moción había sido firmada por varios concejales que ya habian suscrito otra anterior, y considera que si los alcaldes son elegidos por los concejales en la forma que dice el artículo 196 de la referida Ley (Orgánica 5/1985), también pueden ser destituidos conforme se previene en el artículo 197, mediante una moción de censura, con los taxativos e ineludibles requisitos que se detallan en el mismo.

(19) Artículos 6 a 10. En caso de silencio administrativo, el artículo 8 de la Ley 62/1978 establece que, una vez transcurridos veinte dias desde la solicitud ante la Administración, y sin necesidad de denunciar la mora, podrá interponerse el recurso contencioso-administrativo dentro de los diez dias siguientes. 


\section{Posibilidad de presentación de mociones de censura alternativas}

De manera análoga a lo previsto en el artículo 113,3, in fine, de la Constitución, la legislación de régimen local determina que, dentro de los dos días siguientes a la convocatoria de la sesión extraordinaria, podrán presentarse en el Registro General de la Entidad otras mociones de censura alternativas, que deberán reunir los requisitos establecidos en la Ley Orgánica 5/1985, de 19 de junio (20). Es necesario, por tanto, que estas otras mociones de censura al alcalde sean suscritas, cada una, al menos por un tercio de concejales -que han de ser distintos de los que hubiesen firmado la inicialmente formulada $y$, en su caso, otras asimismo concurrentes-, y que además, incluyan distitnos candidatos a la alcaldía. Esta diversidad de candidatos constituye la función principal que cumple la posibilidad de mociones alternativas, en caso de ser presentadas.

Las consecuencias que primordialmente derivan de la presentación de estas otras mociones de censura se hallan, ante todo, en que, al hacerse así una vez efectuada la convocatoria de la sesión extraordinaria, el transcurso del plazo de siete días fijado entre el momento de su presentación y el de celebración de la sesión plenaria sólo se refiere a la moción de censura inicial (21), pero no afecta a las mociones alternativas sino en cuanto a los dos primeros días de dicho plazo, en que éstas podrán presentarse en dicho registro. La razón fundamental de ello se encuentra en que, en este caso, el debate y la votación de las distintas mociones de censura han de ser objeto de consideración y debate en la misma sesión extraordinaria del pleno municipal, evitándose de este modo la reiteración de actuaciones con el mismo objeto, que carecería de sentido y prolongaría innecesariamente la situación.

\section{Informe del Secretario de la Corporación}

Con anterioridad a la celebración de la sesión plenaria, es preceptivo el informe a emitir por el Secretario de la Corporación municipal. Así se deduce del artículo 54,1 ,b) del texto refundido de las disposiciones de régimen local (Real Decreto Legislativo 781/1986, de 18 de abril), que establece que será necesario el informe previo del Secretario para adoptar acuerdos sobre asuntos en materias para las

(20) Artículo 107,4, del Real Decreto 2568/1986, de 28 de noviembre.

(21) Por ello, en la convocatoria de la sesión extraordinaria, efectuada a la vista de esta moción de censura, habrá de prever esta posibilidad, con esta o parecida fórmula: Debate y votación de la moción de censura presentada por... y de las mociones de censura alternativas que, en su caso, se presenten reglamentariamente dentro de los dos siguientes al de la presente convocatoria. 
que se exija una mayoría especial, como sucede en el supuesto que consideramos, en el que la destitución del alcalde mediante moción de censura ha de ser adoptada por la mayoría absoluta del número legal de concejales, según establece la Ley Orgánica 5/1985, en su artículo 197,1 (22). El informe del Secretario habrá de constatar y dictaminar fundamentalmente sobre el cumplimiento por la moción o, en su caso, mociones de censura presentadas, de los requisitos que, según este artículo (apartado 2), han de reunir, para poder ser objeto de debate y votación por el pleno del ayuntamiento en la sesión extraordinaria convocada.

\section{Debate y votación. Efectos en caso de que la moción prospere}

En principio, las normas de procedimiento aplicables a la celebración de la sesión extraordinaria en que ha de tratarse el asunto de la moción de censura serán las normas generales reguladoras del funcionamiento del ayuntamiento como órgano plenario de la entidad municipal. En consecuencia, además de las normas básicas contenidas en la Ley 7/1985, de 2 de abril (arts. 46 y 47) y en el texto refundido de 18 de abril de 1986 (arts. 49 y 50 y disposición final 7.a a), habrá que tener en cuenta que, sin perjuicio de estas normas, aplicables en todo caso en los aspectos correspondientes al régimen de sesiones, por su carácter básico, será aplicable asimismo el reglamento orgánico de la entidad local en lo relativo al debate y votación, si existiere este tipo de reglamento, supuesto que el mismo tiene preferencia sobre el título III del Reglamento de Organización, Funcionamiento y Régimen Jurídico de las Entidades Locales, aprobado por el Real Decreto 2568/1986, cuyas normas son aplicables por ello para suplir el reglamento orgánico municipal, en caso de inexistencia de éste (23).

(22) La sentencia del Tribunal Supremo de 12 de diciembre de 1987 (Arz. 9454), con referencia a un caso resuelto conforme a la legislación de régimen local y electoral precedente a la actual, entiende que al no exigir la jurisprudencia ese quórum de los dos tercios, sino solamente la mayoría absoluta legal de los miembros de la Corporación, interpretación del Tribunal Supremo que adquiere notoria importancia en el caso de autos, puesto que el artículo 4..$^{\circ}$ b) de la Ley $40 / 1981$, de 28 de octubre, sobre régimen jurídico de las Corporaciones Locales, establece la necesidad del informe previo del Secretario, y en su caso, del Interventor, o de quienes legalmente les sustituyan para la adopción de acuerdos sobre materias para las que se exija un quórum especial; quórum no exigible en el presente caso, de acuerdo con las citadas decisiones del Tribunal Supremo, por lo que no procede la estimación de la pretensión de nulidad entablada por la parte actora. (No obstante este pronunciamiento, a nuestro juicio el quórum de votación por mayoría absoluta es un quórum especial -aunque no sea el reforzado de los dos tercios- $y$, por ende, se halla comprendido también en el supuesto en que es preceptivo el informe del Secretario de la Corporación.)

(23) En este sentido, la Resolución interpretativa de la Dirección General de Administración Local, de 27 de enero de 1987, punto núm. 6. En el mismo sentido, el artículo 108,2, del citado Real Decreto 2563/1986, establece que el debate y demás aspectos de procedimiento se regularán por los reglamentos orgánicos de las Entidades Locales. La sentencia del Tribunal 
Supuesto lo anterior, interesa precisar lo siguiente:

- En lo que se refiere al debate, que es muy ilustrativo y puede por ello servir de orientación para completar lo expuesto, el precepto del artículo 177 del Reglamento del Congreso de los Diputados, con las lógicas adaptaciones y limitaciones. En especial, en el caso de haberse presentado mociones de censura alternativas, este precepto determina que, si bien pueden ser objeto de debate conjunto (aquí en la misma sesión, según lo dicho), sin embargo habrán de ser puestas a votación por separado, siguiendo el orden de su presentación; y si se aprobase una moción de censura, no se someterán a votación las restantes que se hubieren presentado.

- De otra parte, en cuanto a la mayoría necesaria, se requiere legalmente que el acuerdo de destitución del alcalde y proclamación del candidato propuesto se adopte por la mayoría absoluta del número legal de concejales (artículo 197,1, de la Ley Orgánica 5/1985). Así se había expresado ya, con anterioridad a esta Ley, la jurisprudencia del Tribunal Supremo, conforme al principio de contrarius actus, es decir, que es suficiente la misma mayoría de concejales requerida para el nombramiento del alcalde que para tomar el acuerdo de su destitución (24).

La aprobación de la moción de censura, por mayoría absoluta, supone no sólo la destitución del alcalde, sino también simultáneamente la elección de quien lo sustituya, quedando proclamado alcalde, por tanto, el candidato que figure en dicha moción (25). Se trata de un solo acto o acuerdo pero que comprende ambos aspectos o, si se quiere, decisiones, a fin de evitar, como dice la sentencia de 14 de enero de 1988 (Arz. 273), que el ayuntamiento no quede vacío de poder. Considera esta sentencia que, siendo un asunto único a debatir y votar «la moción de censura y eventual destitución del alcalde, ello lo era en atención a la propia naturaleza intrínseca que una moción de censura y destitución del Alcalde conlleva, cual es, de prosperar ambas, que el ayuntamiento no quede vacío de poder; por ello, no es necesario celebrar dos plenos distintos sino uno con las sesiones precisas para resolver el asunto a tratar, ya que la destitución de un alcalde precisa, por la razón antes dada, de elección de quien le sustituya, sin que tal proceder acarree la infracción del derecho fundamental alegado, puesto que en lo que al recurrente

Supremo de 30 de mayo de 1986 (arz. 2775) considera improcedente levantar la sesión para impedir la votación de la moción de censura; lo que reitera la sentencia de 12 de mayo de 1987 (Arz. 3333).

(24) Sentencias de 14 de julio de 1983 (Arz. 3993), 10 y 27 de mayo de 1984 (Arz. 1494), 15 de septiembre de 1986 (Arz. 5080), 31 de marzo de 1987 (Arz. 4170 ) y 7 de abril de 1988 (Arz. 2662), entre otras.

(25) El artículo 197,2, de la Ley Orgánica 5/1985 establece que, en caso de prosperar la moción de censura, quedará proclamado alcalde el candidato propuesto (en ella). 
respecta, tal derecho queda concretado en la permanencia en el cargo y su inamovilidad salvo por el voto cualificado de los Concejales que integran la Corporación...».

Al tener carácter automático — «ope legis»-, en caso de prosperar la moción de censura, la proclamación del candidato, en ella propuesto como alcalde, la adopción del acuerdo municipal determinará también, como es lógico, el cese del anterior alcalde, que queda destituido. El Reglamento de Organización, Funcionamiento y Régimen Jurídico de las Entidades Locales determina, por ello, en su artículo 40,6 , que en el supuesto de que prospere una moción de censura contra el alcalde, éste cesará en su cargo en el momento de la adopción del acuerdo, y que quien resulte proclamado como alcalde deberá tomar posesión del cargo en la forma establecida en los apartados 2 y 3 de este artículo; esto es, la toma de posesión se realizará ante el pleno de la Corporación, según la forma general establecida para este tipo de acto para los cargos públicos, y si no se hallare presente en la sesión será requerido para hacerlo en el plazo de cuarenta y ocho horas, ante el pleno corporativo, con la advertencia de que, caso de no hacerlo sin causa justificada, se estará a lo dispuesto en la legislación electoral para los casos de vacante en el alcaldía (26).

\section{REVISION JUDICIAL DEL ACUERDO DE DESTITUCION}

La competencia para fiscalizar el acuerdo de aprobación de la moción de censura y, con ello, la sustitución del alcalde anterior por el candidato que figura en aquélla, corresponde a la Sala de lo Contencioso-Administrativo del correspondiente Tribunal Superior de Justicia, en única instancia, conforme determina el artículo 74,1,d, de la Ley Orgánica 6/1985, de 1 de julio, del Poder Judicial, en relación con el artículo 109 de Ley Orgánica 5/1985, de Régimen Electoral General (27), a través del recurso contencioso-electoral regulado en esta última Ley, en cuanto que su objeto se refiere a la elección y proclamación del presidente de la corporación local.

(26) Lo que determinará, en este caso, la aplicación de lo previsto en el artículo 196 de la Ley Orgánica 5/1985, a que reenvia el 198 de la misma, considerándose que a estos efectos encabeza la lista en que figuraba el alcalde el siguiente de la misma. Reenvío que plantea el problema de que, si bien según el sistema general del artículo 196, habría que considerar cabeza de lista al concejal siguiente que figura en la del alcalde saliente, esta solución podrá plantear. en el caso de vacante por cese debido a la aprobación de una moción de censura, que al no tener la lista de éste mayoria absoluta, no pueda ser elegido y haya de acudir muy probablemente no al siguiente de la lista del alcalde saliente - el censurado y destituido-, sino a otro concejal perteneciente a la nueva mayoría.

(27) En este sentido, Astarloa huarte-Mendicoa, I.: Comentarios a la Ley Orgánica de Régimen Electoral General (dir. por Cazorla Prieto, L. M. ${ }^{\circ}$ ), Civitas, 1986, pp. 1713 y s. PALOMAR OLMEDA, A.: «Aspectos orgánicos y competenciales de la reforma del contencioso-administrativon, en Revista de Administración Pública, núm. 119 (mayo-agosto 1989), p. 444. 
No es, en consecuencia, procedente utilizar la vía de la Ley Orgánica 62/1978, de 26 de diciembre, sobre protección de los derechos fundamentales, a pesar de las dudas que a este respecto se habian planteado (28) y que hoy hay que entender superadas. En algunos casos de cese del alcalde a través de moción de censura, anteriores a la legislación orgánica citada en el párrafo anterior, el Tribunal Supremo ya se había pronunciado, por lo demás, respecto a la improcedencia de seguir la vía jurisdiccional de protección de los derechos fundamentales, por entender que el artículo 23 de la Constitución consagra el derecho de los ciudadanos a acceder a los cargos públicos en condiciones de igualdad, lo que puede aplicarse a ocupar el cargo de concejal o el cargo de alcalde, pero no el derecho a permanecer en el mismo: La sentencia de 15 de julio de 1986 (Arz. 4431 ) así lo considera y dice que no puede entenderse infringido el artículo 23 por el hecho de que el alcalde elegido haya sido cesado en virtud de moción de censura de los concejales, ya que ello, frente a ła opinión del apelante, no implica desconocimiento de los derechos de los ciudadanos a participar en los asuntos públicos cuando esta participación se hace mediante elecciones con objeto de elegir a sus representantes. Los votantes - añade- ejercieron su derecho al voto sin impedimento alguno, y el alcalde fue elegido conforme a lo que la legislación electoral aplicable establecía, por lo que en todo momento se respetó el derecho constitucionalmente protegido de participar en los asuntos públicos por sí o por medio de representantes. Ahora bien, el hecho de que con posterioridad, el designado en virtud de una elección de primero o segundo grado sea cesado en virtud de una moción de censura, es una cuestión ajena a la participación de los ciudadanos en los asuntos públicos y pertenece a la esfera del derecho municipal, porque esa participación ciudadana en los asuntos públicos se agota en la votación, mientras que la permanencia en el cargo es cuestión ajena a los votantes, quienes en caso de aceptarse la tesis de los apelantes, también verían lesionados sus derechos constitucionales en caso de renuncia al cargo o incluso de fallecimiento.

(28) Santolaya Machetti, P.: «Nota en torno a la posibilidad de cese de los alcaldes mediante la aprobación de una moción de censura», en Revista de Administración Pública, núm. 108, pp. 265 y s. 